\title{
Update on Oral Appliance Therapy for OSA
}

\author{
M. Marklund ${ }^{1}$
}

Published online: 10 July 2017

(C) The Author(s) 2017. This article is an open access publication

\begin{abstract}
Purpose of Review The majority of the adult population is affected by obstructive sleep apnea (OSA), according to recent epidemiological research. Oral appliance (OA) therapy is increasingly recommended, particularly for patients with milder OSA. This review updates the evidence in favor of OA therapy. Recent Findings A high level of evidence shows that OA is effective in the treatment of OSA, but continuous positive airway pressure (CPAP) is more efficient. Higher adherence with OAs may compensate for this difference. Daytime sleepiness is better treated with CPAP than with OA in patients with severe OSA. In patients with milder OSA, it is unclear whether sleepiness is significantly reduced. The long-term effectiveness of OAs is uncertain because of side-effects and the risk of OSA deterioration. Summary OAs are effective, but their efficacy is more variable than that of CPAP. More research is needed about the mechanism of action of OA, subjective effects and longterm health outcomes.
\end{abstract}

Keywords Oral appliances · Mandibular advancement devices $\cdot$ Mandibular repositioning appliances

\section{Introduction}

Obstructive sleep apnea (OSA) is highly prevalent in the adult population [1]. Eighty-four per cent of men and $61 \%$ of

This article is part of the Topical Collection on Sleep and Otolaryngology

M. Marklund

marie.marklund@umu.se

1 Department of Odontology, Medical Faculty, Umeå University, SE-906 87 Umeå, Sweden women aged 40 years or older have an apnea-hypopnea index (AHI) of $\geq 5$. A slightly lower prevalence is found, if symptoms or comorbidities such as hypertension are included in the diagnosis [2]. The majority of the subjects have milder forms of the disease, particularly in the younger age groups $[1,2]$. These high numbers of potential patients have initiated a discussion about treatment needs in those with milder forms of the disease [3]. Oral appliances (OAs) have become an increasingly common alternative for patients with OSA of varying severity, although mainly those with milder OSA. Consequently, there is a need for a continuous update of knowledge about the various aspects of this therapy. This review will summarize the present evidence relating to OA treatment and elucidate some areas that are as yet less well studied. Examples of these topics include the more exact indications, patient-oriented aspects of the therapy in terms of symptomatic effects, side-effects, the importance of device design, and the long-term health outcomes.

\section{Mechanism of Action}

Oral appliances reposition the lower jaw forwards in order to increase the upper airway volume and reduce pharyngeal collapsibility [4]. The upper airway enlarges, particularly in its lateral dimension at velopharyngeal level, and the tongue is displaced anteriorly [4-6]. Various underlying pathophysiologies between OSA patients are differently affected by the mechanism of action of OAs. OSA patients may suffer, to varying degrees, from upper airway anatomical abnormalities, increased pharyngeal collapsibility, an overly sensitive ventilatory control system (high loop gain), and a reduced arousal threshold [7•]. OAs improve pharyngeal collapsibility, while loop gain, arousal threshold, and dilator muscular activity are unchanged $[8 \bullet \bullet$. Patients with mild OSA are thought to be 
better suited to the mechanism of OAs than patients with more severe OSA. They generally have less collapsible airways [7•, $8 \bullet \cdot$, and their pharynx will increase more, along the whole of its length, compared with patients with more severe disease [9].

In conclusion, the mechanism of action of OAs is less predictable than that of continuous positive airway pressure (CPAP), even in the longer term $[10 \bullet, 11 \bullet \bullet, 12]$. An OA can therefore be used as a sole treatment or in combination with other sleep apnea treatments such as CPAP or positional therapy, when the treatment is not totally successful in itself [13, $14,15 \cdot]$. On the other hand, an OA can help to reduce the sideeffects of CPAP machines in patients who suffer from uncomfortably high pressures $[16,17]$.

\section{Short-Term Effects on Apneas and Hypopneas}

The apnea-hypopnea index is effectively reduced by OA compared with placebo interventions $[11 \bullet \cdot$. The nightly oxygenation is improved $[10 \bullet, 11 \bullet \bullet$. Treatment with CPAP is more effective than $\mathrm{OA}$ treatment in reducing the $\mathrm{AHI}$, according to all the studies comprising patients with mild to severe OSA $[10 \bullet \cdot, 11 \bullet \cdot$. With CPAP, the nightly oxygenation is further restored compared with OA $[10 \bullet \cdot$.

\section{Predicting Success}

In general, larger repositioning of the lower jaw forwards will have a better effect on the apnea-hypopnea index, although there is no linear relationship [18]. Differences in the ability to advance the lower jaw forwards between patients will therefore, to some extent, modify the potential to reduce or eliminate obstructive sleep apneas. Milder OSA patients have a greater chance of treatment success with OA therapy than patients with severe OSA. In this group of patients, the success rate is fairly equal between OA and CPAP [19, 20]. Severe OSA patients can be successfully treated with OA [19], but CPAP is more likely to eliminate obstructive sleep apneas and hypopneas in these patients $[10 \bullet, 11 \bullet \bullet]$. OAs can, however, be recommended as a second line treatment in CPAP-intolerant patients $[21,22]$.

A new approach to predicting treatment success with OAs highlights the variability in OSA pathophysiology between patients. Patients with less collapsible upper airways and a less sensitive ventilatory control system are more likely to benefit from OA therapy $[7 \cdot, 8 \bullet \bullet]$. Patients with milder OSA have, in general, a better passive upper airway anatomy and a less collapsible airway, but may differ in the presence of nonanatomic traits [7•]. These characteristics might therefore constitute useful additional negative predictors of success for OA therapy in this group of patients.
In line with these results, good prediction potential has been detected by the verified widening of the pharynx visualized by nasendoscopy [6,23-25] or a sufficient reduction in AHI during an overnight test with a remotely controlled device [26•, 27].

Results from clinical routine such as a lower CPAP pressure $[28,29]$ or existing supine-position-dependent sleep apnea can also be useful predictors of success [30-34]. Some conflicting results about the value of supine dependency as a predictor of success can probably be explained by differences in the potential of various devices to stabilize the lower jaw in a forward position during sleep. The fixation of the lower jaw to the upper jaw to achieve the intended forward repositioning might be particularly important in the supine position [35].

Lower age or non-obesity at baseline or female sex have been related to success, although these predictors have variable strength and represent less useful predictors in clinical practice $[20,32,36]$. Weight increase during treatment has, however, been related to treatment failure [32]. Cephalometric evaluations of morphological variables are inconsistent predictors of success [37॰]. Elderly people may be satisfactorily treated with OAs, although there are few studies in this area [38].

In conclusion, there is a high level of evidence of a satisfactory effect on sleep apnea by OAs. The variability in treatment response means, however, that CPAP will always represent a more efficient alternative. It is therefore important for the future to find validated predictors of a successful apnea-hypopnea reduction with OA treatment. Until more knowledge is available, snoring and mild to moderate OSA constitute the primary indications for OA treatment. A confirmed widening of the upper airway or AHI reduction during a prediction test can also be used, if the methodology is clinically available.

\section{Symptomatic Effects}

The effect on daytime sleepiness from obstructive sleep apnea treatments is unclear, particularly in subjects within the mildest spectrum of disease severity. Many patients report less daytime sleepiness according to the Epworth Sleepiness Scale (ESS) score with OA treatment compared with not having a device in situ, but some of this may be related to placebo effects $[39,40 \cdot, 41]$. In the nine randomized controlled studies $[39,40 \cdot, 41-47]$ that compare OA with an intraoral placebo device, only one cross-over study found a significant difference in the ESS score between OA and a placebo device [39]. None of the five parallel RCT studies reported a lower ESS score with OA compared with a placebo device $[40 \cdot, 41-43$, 45]. Two randomized controlled studies comprised milder OSA patients; i.e., those who are primarily indicated for this type of therapy. There was no effect on the ESS score compared with placebo intervention in these studies $[40 \bullet, 44]$. One of these two studies concentrated on symptomatic effects, and 
there were no effects on fatigue, prospective reports of daytime sleepiness measured by the Karolinska Sleepiness Scale, objective tests of sleepiness by the Osler test, or quality of life in that study [40•]. The summarized results in a recent metaanalysis report no effect on the ESS score from OAs compared with placebo in a group of patients with moderate sleep apnea $[11 \bullet \cdot$. Nor was there any difference in the ESS score between CPAP and OAs in this group of patients [11••]. No placebo controlled studies of mild OSA patients had been published when this meta-analysis was performed. Consequently, it is uncertain, whether daytime sleepiness and quality of life are significantly reduced by any OSA treatment in patients with milder OSA [11••, 48]. In contrast, patients with more severe OSA experience a reduction in daytime sleepiness as a result of OA compared with a placebo intervention, but CPAP is more effective [11••]. Most likely, mild to moderate OSA causes less pronounced daytime sleepiness than previously assumed, while other conditions and diseases may explain daytime sleepiness. These recent findings also elucidate why as much as one third of patients who are treated with either CPAP or OA are still sleepy, defined as an ESS score of above 10, despite a successful sleep apnea reduction [49, 50•].

Regarding other symptoms that are related to untreated OSA, two studies have found a significant positive effect on symptoms of restless legs by OA treatment versus placebo interventions [40•, 51]. A number of other OSA-related symptoms, such as headaches, nasal congestion, and insomnia, were lower with active treatment than without the device in one of these studies, although there was no difference compared with placebo intervention [40 $]$. Future randomized controlled studies of subgroups of OSA patients are needed to evaluate all the various symptoms that may affect sleep apnea patients. A recent study found that OSA patients that predominantly have sleep arousals more often continue OA treatment than those with predominant desaturations, indicating that the arousal subgroup might experience more subjective advantages from OA treatment [52]. Many symptoms such as insomnia, daytime sleepiness, headaches, and restless legs may coexist with OSA [53-55] and require individualized treatment approaches.

In conclusion, the effect of OAs on daytime sleepiness is uncertain, particularly in snorers and those with mild to moderate OSA, i.e., the group of patients for whom this type of therapy is primarily recommended. It will be important for the future to study various symptomatic effects of OA treatment in relation to phenotype. Maybe there are also other unknown outcomes on sleep of OSA treatment, such as on the glymphatic system [56], that might have an impact on symptoms.

\section{Effects on Snoring}

Patients' interest usually focuses on reducing snoring in order to eliminate disturbances in family life or on journeys. Most studies have reported subjectively registered effects on snoring, although some objective measurements have also been made [39, 47]. Snoring is more effectively controlled by OA than by an intraoral placebo device, while CPAP is more effective than OA [57-59]. Persistent snoring during OA treatment has been related to insufficient apnea control and poor adherence with treatment $[58,60 \bullet]$.

In conclusion, fairly little research has focused on the treatment effects on snoring, probably because of difficulty measuring sounds and less evidence of snoring being related to longer term negative health outcomes [1]. From the patients' perspective, more research on the psychosocial outcomes produced by the treatment of snoring would be of interest.

\section{Health Outcomes}

The health effects of OSA treatments have mainly focused on the cardiovascular effects. Blood pressure is reduced by OAs and to a similar level as with CPAP [61•]. In addition, OA has been found to improve the nightly dips in blood pressure [62, 63]. One small, descriptive study reports a similar mortality rate between patients treated with OA, CPAP, and healthy controls compared with untreated severe OSA patients [64]. A few more studies of small samples report improved endothelial [65, 66] and cardiac function during OA treatment [67].

One reason for the similar effects on cardiovascular health produced by OAs compared with CPAP has been related to the increased preference for and adherence with OA [68]. The use of compliance monitors for OAs in larger studies is needed to determine more exactly the long-term health outcomes of OA compared with CPAP [69]. Important tasks for future research will be to study harder endpoint outcomes of OA treatment in comparison with CPAP.

\section{Side Effects}

Most side-effects of OA treatment are temporary and disappear during the first few months of treatment. Examples of these side-effects include pain and salivation problems [70]. An unforeseen aspect of the risk of side-effects was visualized in a recent study that discovered more muscular pain in the initial part of OA treatment in patients on statin medication than in controls [71].

Tooth movements from the forces that are applied to the teeth constitute the main problem. OAs produce distally directed forces on the upper dentition and forwardly directed ones on the lower teeth. In the long run, there will be a dose-dependent shift in dental occlusion, with the lower teeth moving into a more anterior position, the upper ones moving distally and a loss of chewing contact areas in the posterior parts [72-74]. Almost all patients can be expected to develop a 
decreased overjet and overbite during the first 5 years [75], while around one third of the patients will experience more than $1 \mathrm{~mm}$ of change [76]. Bite changes will increase progressively as long as treatment continues [77•]. In a group of patients that were evaluated after 17 years, the median change in overjet was $-1.1 \mathrm{~mm}$, and the median change in overbite was $-1.6 \mathrm{~mm}[78 \bullet]$. The maximum overjet change in one of these patients was $-5 \mathrm{~mm}$, and the maximum overbite change was $-4 \mathrm{~mm}$ in another patient. Younger and older subjects are affected by bite changes to a similar degree [38], although this depends on oral health and the length of the treatment. Interestingly, only a minority of patients notice these bite changes $[79,80]$, which indicates that they are less disturbing than expected.

In conclusion, bite changes during OA treatment are progressive in nature, and patients may at some time point be disturbed about the esthetics or problems biting or chewing. Most importantly, these bite changes will influence the mechanism of the device, since a forward shift of the lower teeth compared with the upper ones will result in a successively reduced degree of mandibular advancement. This puts the efficacy of the treatment at risk. Consequently, patients must be cared for in an individual way, since they will respond differently to mandibular repositioning during the night. It may be important for the future to study how often patients have to be followed up in order to assess bite changes in relation to the efficacy of the device and the importance of bite changes for oral health.

\section{Long-Term Outcomes}

The efficacy of OAs is fairly stable up to 10 years, according to nine small studies of carefully followed up patients $[12,70$, 81-88] (Fig. 1). After that time, only one study has reported results from a few patients [78•]. In that study, all the patients increased their AHI with the device, and all but one patient increased the AHI without it. The weight of the patients did not increase, and they were not sleepy at the long-term followup. In addition, all OAs had been continuously adjusted with more advancement in order to compensate for the shift in dental occlusion, with the lower teeth successively being located more anteriorly in relation to the upper teeth as a common side-effect of the device. The deterioration in disease severity could have been explained by aging, which is related to an increase in AHI $[89,90]$. It is important to be aware of the fact that the patients' ability to keep their airways patent changes continuously. In addition, bite changes may reduce the actual advancement of the lower jaw and reduce the efficacy of the device. The mechanism of an OA is highly dependent on the pathophysiology of OSA and the actual advancement of the lower jaw. No study has yet presented the longterm effectiveness in a large group of patients treated with
OAs for sleep apnea and evaluated which patients are primary long-term candidates for this kind of treatment and which patients require more intense surveillance.

In conclusion, the effectiveness of an OA will decrease in the longer term, since some patients discontinue treatment because of poor subjective effects or side-effects, and continuing patients may risk a poorer objective treatment effect [91]. It is not the same patient that is treated after a number of years, because of age and bite changes. The mechanism of action of OAs is more vulnerable than that of CPAP, which makes it necessary more continuously to re-evaluate the treatment outcome. Much more research is needed about the long-term outcomes of OA therapy. In addition, it would be of interest to study oral health during OSA treatment, i.e., whether oral health improves or deteriorates as a result of the treatment, and, in that case, in which patients, or whether both things occur in the majority.

\section{OA Design}

OAs exists in many different designs, and few studies have dealt with the influence of various design details on the efficacy and side-effects of the treatment. The most common and effective [36] types of device, the titrable ones, are constructed into two parts. There is an upper part and a lower one, with an intermaxillary adjustment mechanism between them in order to allow the lower jaw to be moved forward successively and find an optimal mandibular position. The two parts may be fixed to one another, with a screw mechanism, for example, or the lower jaw may be allowed to move laterally and/or vertically. Studies have indicated that appliances that allows mouth opening are less effective in reducing sleep apnea [35, 92]. One of these studies tested, in a small sample, the influence of elastics to hold the jaws together in a specific device that allowed mouth opening in its original design [35]. Most patients experienced no difference in efficacy, while two patients with severe disease experienced a halving of apnea frequency in the supine position with the elastics in place compared with not having them. The use of non-individualized appliances cannot be recommended, based on the present level of knowledge $[93,94]$. The retention of these non-individualized devices is often poorer than with a custom-made design [94], although this might be improved in the future [95].

Side-effects and patients' experiences have been sparsely evaluated in relation to device design. One study reports that patients stop treatment because of uncomfortable appliances [96], a fact that is of great importance to treatment outcome.

The degree of bite changes is influenced by appliance design, in addition to the initial type of bite and treatment time. One study revealed no change in overjet and overbite after 4year treatment [97]. That study used a specific OA design, with a lack of buccal coverage on the upper incisors and 
Fig. 1 Efficacy in 10 long-term studies of OA treatment (the data refer to AHI, when not otherwise stated. $*$ = baseline value from a larger sample)

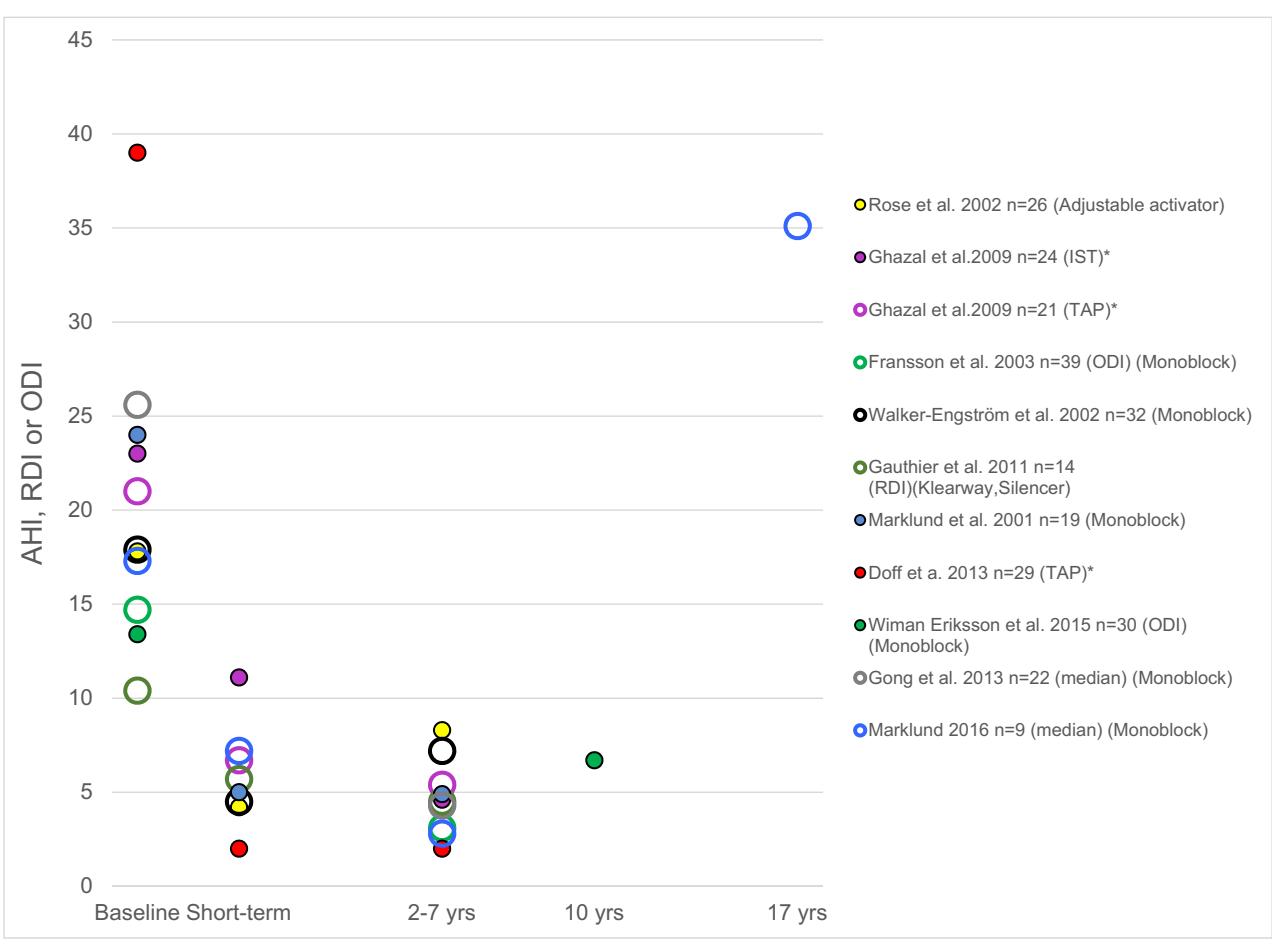

enforced lower incisor coverage. An observational study found fewer changes in overjet and overbite with a soft elastomeric device that covered some parts of the alveolar processes in addition to all the teeth compared with a hard acrylic OA with full occlusal coverage that was mainly fixed to the teeth [76]. A specific orthodontic oral appliance with incorporated forces to counteract the posteriorly directed forces on the upper front teeth had a positive effect on overjet changes compared with a control device in a small group of patients [98]. Most likely, a number of design details will influence the treatment outcome and side-effects in several ways.

In conclusion, there are numerous OA designs and a lack of identified golden standard types of device. Custom-made, titrable OAs that do not allow mouth opening are primarily recommended today. Prefabricated devices often have poor retention and are therefore not suitable as test devices either. Although much is already known about the outcome of OAs in the treatment of OSA, knowledge about various device designs is still lacking.

\section{Other Aspects of the Treatment}

The recent article by McNicholas et al. [3] discusses indications for treatment in patients with milder disease. In the light of the large numbers of patients that are affected by the disorder and whether it is healthy always to eliminate sleep apneas in all patients, the more exact indications were discussed [99•].

The role of sleeping together has been elucidated in a recent review article [100]. Differences in diurnal preferences and
Chrono types between individuals, genders, and cultural norms may affect daytime functioning and relationships. The article stresses that bed partners should be more directly involved in various treatment options for different sleep disorders, among which snoring and breathing pauses during sleep constitute an important part. It would be interesting to study adherence and motivation with sleep apnea treatments in relation to this topic in more detail [101].

\section{Conclusions}

OAs reduce sleep apneas and are an effective treatment for selected patients.

Upper airway pathophysiology, such as pharyngeal collapsibility and verified widening by mandibular advancement, constitute promising predictors of success for the effects of OA therapy.

The effects on daytime sleepiness by OAs are uncertain and are influenced by OSA severity and other causes of sleepiness.

There are promising effects on cardiovascular health by OA therapy.

Bite changes occur in almost all patients, although they tend to be minor and do generally not disturb the patients.

The influence of device design on the efficacy and sideeffects of OAs is almost unknown.

Long-term efficacy is good up to 10 years in wellcontrolled samples, but it probably declines in the real-life, long-term perspective. The natural development of the disease usually results in a deterioration in AHI. Effectiveness 
declines, with patients discontinuing treatment because of poor subjective treatment effect or side-effects, or poorer outcomes in follow-up sleep apnea recordings.

\section{Future Research}

It is time to look at the outcomes of OAs in various phenotypes of obstructive sleep apnea patients.

More validation of predictors is needed.

More studies of the symptomatic effects of OSA treatments are needed, since they are still elusive.

Bite changes might influence the mechanism of the device, and methods to minimize these adverse effects are needed.

The many designs of OAs require comparison in terms of efficacy, stability, and side-effects.

The longer term outcomes in various areas, in particular cardiovascular health and mortality in real life, should be studied. The "Orange" project will shed light on the real-life outcomes of OA therapy, also in the longer term [102].

\section{Compliance with Ethical Standards}

Conflict of Interest Marie Marklund reports a consultancy fee from ResMed.

Human and Animal Rights and Informed Consent This article does not contain any studies with human or animal subjects performed by any of the authors.

Open Access This article is distributed under the terms of the Creative Commons Attribution 4.0 International License (http:// creativecommons.org/licenses/by/4.0/), which permits unrestricted use, distribution, and reproduction in any medium, provided you give appropriate credit to the original author(s) and the source, provide a link to the Creative Commons license, and indicate if changes were made.

\section{References}

Papers of particular interest, published recently, have been highlighted as:

- Of importance

•- Of major importance

1. Heinzer R, Vat S, Marques-Vidal P, Marti-Soler H, Andries D, Tobback N, et al. Prevalence of sleep-disordered breathing in the general population: the HypnoLaus study. Lancet Respir Med. 2015;3:310-8. doi:10.1016/S2213-2600(15)00043-0.

2. Heinzer R, Marti-Soler H, Haba-Rubio J. Prevalence of sleep apnoea syndrome in the middle to old age general population. Lancet Respir Med. 2016;4:e5-6. doi:10.1016/S2213-2600(16)00006-0.

3. McNicholas WT, Bonsignore MR, Levy P, Ryan S. Mild obstructive sleep apnoea: clinical relevance and approaches to management. Lancet Respir Med. 2016;4:826-34. doi:10.1016/S22132600(16)30146-1.
4. Sutherland K, Chan AS, Cistulli PA. Three-dimensional assessment of anatomical balance and oral appliance treatment outcome in obstructive sleep apnoea. Sleep Breath. 2016;20:903-10. doi: 10.1007/s11325-015-1304-x.

5. Gakwaya S, Melo-Silva CA, Borel JC, Rousseau E, Masse JF, Series F. Impact of stepwise mandibular advancement on upper airway mechanics in obstructive sleep apnea using phrenic nerve magnetic stimulation. Respir Physiol Neurobiol. 2014;190:131-6. doi:10.1016/j.resp.2013.10.004.

6. Sasao Y, Nohara K, Okuno K, Nakamura Y, Sakai T. Videoendoscopic diagnosis for predicting the response to oral appliance therapy in severe obstructive sleep apnea. Sleep Breath. 2014;18:809-15. doi:10.1007/s11325-014-0947-3.

7. Edwards BA, Eckert DJ, Jordan AS. Obstructive sleep apnoea pathogenesis from mild to severe: is it all the same? Respirology. 2017;22:33-42. doi:10.1111/resp.12913. Article providing more deep insights in OSA patophysiology in relation to desease severity

8.• Edwards BA, Andara C, Landry S, Sands SA, Joosten SA, Owens RL, et al. Upper-airway collapsibility and loop gain predict the response to oral appliance therapy in obstructive sleep apnea patients. Am J Respir Crit Care Med. 2016;194:1413-22. doi:10. 1164/rccm.201601-0099OC. The first study of physiological traits as predictors of $\mathrm{OA}$ success compared with more traditional ones

9. Brown EC, Cheng S, McKenzie DK, Butler JE, Gandevia SC, Bilston LE. Tongue and lateral upper airway movement with mandibular advancement. Sleep. 2013;36:397-404. doi:10.5665/ sleep. 2458 .

10.• Ramar K, Dort LC, Katz SG, Lettieri CJ, Harrod CG, Thomas $\mathrm{SM}$, et al. Clinical practice guideline for the treatment of obstructive sleep apnea and snoring with oral appliance therapy: an update for 2015. J Clin Sleep Med. 2015;11:773-827. doi:10.5664/ jcsm.4858. The most recent guideline regarding OA therapy

11.• Sharples LD, Clutterbuck-James AL, Glover MJ, Bennett MS, Chadwick R, Pittman MA, et al. Meta-analysis of randomised controlled trials of oral mandibular advancement devices and continuous positive airway pressure for obstructive sleep apnoeahypopnoea. Sleep Med Rev. 2016;27:108-24. doi:10.1016/j. smrv.2015.05.003. The most recent meta-analysis regarding OA therapy

12. Aarab G, Lobbezoo F, Heymans MW, Hamburger HL, Naeije M. Long-term follow-up of a randomized controlled trial of oral appliance therapy in obstructive sleep apnea. Respiration. 2011;82: 162-8. doi:10.1159/000324580.

13. Almeida FR, Henrich N, Marra C, Lynd LD, Lowe AA, Tsuda H, et al. Patient preferences and experiences of CPAP and oral appliances for the treatment of obstructive sleep apnea: a qualitative analysis. Sleep Breath. 2013;17:659-66. doi:10.1007/s11325012-0739-6.

14. El-Solh AA, Moitheennazima B, Akinnusi ME, Churder PM, Lafornara AM. Combined oral appliance and positive airway pressure therapy for obstructive sleep apnea: a pilot study. Sleep Breath. 2011;15:203-8. doi:10.1007/s11325-010-0437-1.

15. Dieltjens M, Vroegop AV, Verbruggen AE, Wouters K, Willemen $\mathrm{M}$, De Backer WA, et al. A promising concept of combination therapy for positional obstructive sleep apnea. Sleep Breath. 2015;19:637-44. doi:10.1007/s11325-014-1068-8. Study highlighting the possibilities to combine treatments

16. Borel JC, Gakwaya S, Masse JF, Melo-Silva CA, Series F. Impact of CPAP interface and mandibular advancement device on upper airway mechanical properties assessed with phrenic nerve stimulation in sleep apnea patients. Respir Physiol Neurobiol. 2012;183:170-6. doi:10.1016/j.resp.2012.06.018.

17. Kaminska M, Montpetit A, Mathieu A, Jobin V, Morisson F, Mayer P. Higher effective oronasal versus nasal continuous 
positive airway pressure in obstructive sleep apnea: effect of mandibular stabilization. Can Respir J. 2014;21:234-8.

18. Bartolucci ML, Bortolotti F, Raffaelli E, D'Anto V, Michelotti A, Alessandri Bonetti G. The effectiveness of different mandibular advancement amounts in OSA patients: a systematic review and meta-regression analysis. Sleep Breath. 2016;20:911-9. doi:10. 1007/s11325-015-1307-7.

19. Hoekema A, Stegenga B, Wijkstra PJ, van der Hoeven JH, Meinesz AF, de Bont LG. Obstructive sleep apnea therapy. J Dent Res. 2008;87:882-7.

20. Holley AB, Lettieri CJ, Shah AA. Efficacy of an adjustable oral appliance and comparison with continuous positive airway pressure for the treatment of obstructive sleep apnea syndrome. Chest. 2011;140:1511-6. doi:10.1378/chest.10-2851.

21. Gjerde K, Lehmann S, Berge ME, Johansson AK, Johansson A. Oral appliance treatment in moderate and severe obstructive sleep apnea patients non-adherent to CPAP. J Oral Rehabil. 2016;43: 249-58. doi:10.1111/joor.12376.

22. Haviv Y, Bachar G, Aframian DJ, Almoznino G, Michaeli E, Benoliel R. A 2-year mean follow-up of oral appliance therapy for severe obstructive sleep apnea: a cohort study. Oral Dis. 2015;21:386-92. doi:10.1111/odi.12291.

23. Okuno K, Pliska BT, Hamoda M, Lowe AA, Almeida FR. Prediction of oral appliance treatment outcomes in obstructive sleep apnea: a systematic review. Sleep Med Rev. 2015;30:2533. doi:10.1016/j.smrv.2015.11.007.

24. Vroegop AV, Vanderveken OM, Dieltjens M, Wouters K, Saldien $\mathrm{V}$, Braem MJ, et al. Sleep endoscopy with simulation bite for prediction of oral appliance treatment outcome. J Sleep Res. 2013;22:348-55. doi:10.1111/jsr.12008.

25. De Corso E, Bastanza G, Della Marca G, Grippaudo C, Rizzotto G, Marchese MR, et al. Drug-induced sleep endoscopy as a selection tool for mandibular advancement therapy by oral device in patients with mild to moderate obstructive sleep apnoea. Acta Otorhinolaryngol Ital. 2015;35:426-32. doi:10.14639/0392100X-959.

26. Kastoer C, Dieltjens M, Oorts E, Hamans E, Braem MJ, Van de Heyning PH, et al. The use of remotely controlled mandibular positioner as a predictive screening tool for mandibular advancement device therapy in patients with obstructive sleep apnea through single-night progressive titration of the mandible: a systematic review. J Clin Sleep Med. 2016;12:1411-21. doi:10.5664/ jcsm.6202. Important review about a remotely controlled device

27. Remmers J, Charkhandeh S, Grosse J, Topor Z, Brant R, Santosham P, et al. Remotely controlled mandibular protrusion during sleep predicts therapeutic success with oral appliances in patients with obstructive sleep apnea. Sleep. 2013;36:1517-1525, 25A. doi:10.5665/sleep.3048.

28. Sutherland K, Phillips CL, Davies A, Srinivasan VK, Dalci O, Yee $\mathrm{BJ}$, et al. CPAP pressure for prediction of oral appliance treatment response in obstructive sleep apnea. J Clin Sleep Med. 2014;10: 943-9. doi:10.5664/jcsm.4020.

29. Tsuiki S, Kobayashi M, Namba K, Oka Y, Komada Y, Kagimura $\mathrm{T}$, et al. Optimal positive airway pressure predicts oral appliance response to sleep apnoea. Eur Respir J. 2010;35:1098-105. doi: 10.1183/09031936.00121608.

30. Dieltjens M, Braem MJ, Van de Heyning PH, Wouters K, Vanderveken OM. Prevalence and clinical significance of supine-dependent obstructive sleep apnea in patients using oral appliance therapy. J Clin Sleep Med. 2014;10:959-64. doi:10. $5664 /$ jcsm. 4024.

31. Lee CH, Jung HJ, Lee WH, Rhee CS, Yoon IY, Yun PY, et al. The effect of positional dependency on outcomes of treatment with a mandibular advancement device. Arch Otolaryngol Head Neck Surg. 2012;138:479-83. doi:10.1001/archoto.2012.452.
32. Marklund M, Stenlund H, Franklin KA. Mandibular advancement devices in 630 men and women with obstructive sleep apnea and snoring: tolerability and predictors of treatment success. Chest. 2004; 125:1270-8.

33. Sutherland K, Takaya H, Qian J, Petocz P, Ng AT, Cistulli PA. Oral appliance treatment response and polysomnographic phenotypes of obstructive sleep apnea. J Clin Sleep Med. 2015;11:861-8. doi: $10.5664 /$ jcsm. 4934 .

34. Takaesu Y, Tsuiki S, Kobayashi M, Komada Y, Nakayama H, Inoue Y. Mandibular advancement device as a comparable treatment to nasal continuous positive airway pressure for positional obstructive sleep apnea. J Clin Sleep Med. 2016;12:1113-9. doi: 10.5664/jcsm.6048.

35. Norrhem N, Marklund M. An oral appliance with or without elastic bands to control mouth opening during sleep-a randomized pilot study. Sleep Breath. 2016;20:929-38. doi:10.1007/s11325016-1312-5.

36. Lettieri CJ, Paolino N, Eliasson AH, Shah AA, Holley AB. Comparison of adjustable and fixed oral appliances for the treatment of obstructive sleep apnea. J Clin Sleep Med. 2011;7:439 45. doi:10.5664/JCSM.1300.

37. Denolf PL, Vanderveken OM, Marklund ME, Braem MJ. The status of cephalometry in the prediction of non-CPAP treatment outcome in obstructive sleep apnea patients. Sleep Med Rev. 2016;27:56-73. doi:10.1016/j.smrv.2015.05.009. Comprehensive review about the possibilites to predict success with $\mathrm{OA}$ therapy based on cephalograms

38. Marklund M, Franklin KA. Treatment of elderly patients with snoring and obstructive sleep apnea using a mandibular advancement device. Sleep Breath. 2015;19:403-5. doi:10.1007/s11325014-0987-8.

39. Gotsopoulos H, Chen C, Qian J, Cistulli PA. Oral appliance therapy improves symptoms in obstructive sleep apnea: a randomized, controlled trial. Am J Respir Crit Care Med. 2002;166:743-8.

40. Marklund M, Carlberg B, Forsgren L, Olsson T, Stenlund H, Franklin KA. Oral appliance therapy in patients with daytime sleepiness and snoring or mild to moderate sleep apnea: a randomized clinical trial. JAMA Intern Med. 2015;175:1278-85. doi:10. 1001/jamainternmed.2015.2051. The first study of symptomatic effects of OAs in patients with milder OSA; i.e. those with primary indications for this therapy

41. Petri N, Svanholt P, Solow B, Wildschiodtz G, Winkel P. Mandibular advancement appliance for obstructive sleep apnoea: results of a randomised placebo controlled trial using parallel group design. J Sleep Res. 2008;17:221-9. doi:10.1111/j.13652869.2008.00645.x.

42. Aarab G, Lobbezoo F, Hamburger HL, Naeije M. Oral appliance therapy versus nasal continuous positive airway pressure in obstructive sleep apnea: a randomized, placebo-controlled trial. Respiration. 2011;81:411-9. doi:10.1159/000319595.

43. Blanco J, Zamarron C, Abeleira Pazos MT, Lamela C, Suarez Quintanilla D. Prospective evaluation of an oral appliance in the treatment of obstructive sleep apnea syndrome. Sleep Breath. 2005;9:20-5. doi:10.1007/s11325-005-0003-4.

44. Duran-Cantolla J, Crovetto-Martinez R, Alkhraisat MH, Crovetto M, Municio A, Kutz R, et al. Efficacy of mandibular advancement device in the treatment of obstructive sleep apnea syndrome: a randomized controlled crossover clinical trial. Med Oral Patol Oral Cir Bucal. 2015;20:e605-15.

45. Hans MG, Nelson S, Luks VG, Lorkovich P, Baek SJ. Comparison of two dental devices for treatment of obstructive sleep apnea syndrome (OSAS). Am J Orthod Dentofac Orthop. 1997;111:562-70.

46. Johnston CD, Gleadhill IC, Cinnamond MJ, Gabbey J, Burden DJ. Mandibular advancement appliances and 
obstructive sleep apnoea: a randomized clinical trial. Eur J Orthod. 2002;24:251-62.

47. Mehta A, Qian J, Petocz P, Darendeliler MA, Cistulli PA. A randomized, controlled study of a mandibular advancement splint for obstructive sleep apnea. Am J Respir Crit Care Med. 2001;163: 1457-61.

48. Batool-Anwar S, Goodwin JL, Kushida CA, Walsh JA, Simon $\mathrm{RD}$, Nichols DA, et al. Impact of continuous positive airway pressure (CPAP) on quality of life in patients with obstructive sleep apnea (OSA). J Sleep Res. 2016;25:731-8. doi:10.1111/jsr.12430.

49. Antic NA, Catcheside P, Buchan C, Hensley M, Naughton MT, Rowland $\mathrm{S}$, et al. The effect of CPAP in normalizing daytime sleepiness, quality of life, and neurocognitive function in patients with moderate to severe OSA. Sleep. 2011;34:111-9.

50. Verbruggen AE, Dieltjens M, Wouters K, De Volder I, Van de Heyning PH, Braem MJ, et al. Prevalence of residual excessive sleepiness during effective oral appliance therapy for sleepdisordered breathing. Sleep Med. 2014;15:269-72. doi:10.1016/ j.sleep.2013.11.781. Study describing residual daytime sleepiness despite a sufficient AHI-reduction of OA therapy

51. Saletu A, Anderer P, Parapatics S, Matthai C, Matejka M, Saletu B. Effects of a mandibular repositioning appliance on sleep structure, morning behavior and clinical symptomatology in patients with snoring and sleep-disordered breathing. Neuropsychobiology. 2007;55:184-93. doi:10.1159/000107071.

52. Nerfeldt P, Friberg D. Effectiveness of oral appliances in obstructive sleep apnea with respiratory arousals. J Clin Sleep Med. 2016;12:1159-65. doi:10.5664/jcsm.6058.

53. Roux FJ. Restless legs syndrome: impact on sleep-related breathing disorders. Respirology. 2013;18:238-45. doi:10.1111/j.14401843.2012.02249.x.

54. Suzuki K, Miyamoto M, Miyamoto T, Numao A, Suzuki S, Sakuta H, et al. Sleep apnoea headache in obstructive sleep apnoea syndrome patients presenting with morning headache: comparison of the ICHD-2 and ICHD-3 beta criteria. J Headache Pain. 2015;16:56. doi:10.1186/s10194-015-0540-6.

55. Saaresranta T, Hedner J, Bonsignore MR, Riha RL, McNicholas WT, Penzel T, et al. Clinical phenotypes and comorbidity in European sleep apnoea patients. PLoS One. 2016;11:e0163439. doi:10.1371/journal.pone.0163439.

56. Jessen NA, Munk AS, Lundgaard I, Nedergaard M. The Glymphatic system: a beginner's guide. Neurochem Res. 2015;40:2583-99. doi:10.1007/s11064-015-1581-6.

57. Ferguson KA, Ono T, Lowe AA, al-Majed S, Love LL, Fleetham JA. A short-term controlled trial of an adjustable oral appliance for the treatment of mild to moderate obstructive sleep apnoea. Thorax. 1997;52:362-8.

58. Ferguson KA, Ono T, Lowe AA, Keenan SP, Fleetham JA. A randomized crossover study of an oral appliance vs nasalcontinuous positive airway pressure in the treatment of mildmoderate obstructive sleep apnea. Chest. 1996;109:1269-75.

59. Gagnadoux F, Fleury B, Vielle B, Petelle B, Meslier N, N'Guyen $\mathrm{XL}$, et al. Titrated mandibular advancement versus positive airway pressure for sleep apnoea. Eur Respir J. 2009;34:914-20. doi:10. 1183/09031936.00148208.

60. Dieltjens M, Verbruggen AE, Braem MJ, Wouters K, Verbraecken JA, De Backer WA, et al. Determinants of objective compliance during oral appliance therapy in patients with sleep-disordered breathing: a prospective clinical trial. JAMA Otolaryngol Head Neck Surg. 2015;141:894-900. doi:10.1001/jamaoto.2015.1756. First study of predictors of objective compliance

61. Bratton DJ, Gaisl T, Wons AM, Kohler M. CPAP vs mandibular advancement devices and blood pressure in patients with obstructive sleep apnea: a systematic review and meta-analysis. JAMA. 2015;314:2280-93. doi:10.1001/jama.2015.16303. Up-to-date meta-analysis of the effects on blood pressure of OA compared with CPAP

62. Barnes M, McEvoy RD, Banks S, Tarquinio N, Murray CG, Vowles N, et al. Efficacy of positive airway pressure and oral appliance in mild to moderate obstructive sleep apnea. Am J Respir Crit Care Med. 2004;170:656-64. doi:10.1164/rccm. 200311-15710C.

63. Dal-Fabbro C, Garbuio S, D'Almeida V, Cintra FD, Tufik S, Bittencourt L. Mandibular advancement device and CPAP upon cardiovascular parameters in OSA. Sleep Breath. 2014;18:749 59. doi:10.1007/s11325-014-0937-5.

64. Anandam A, Patil M, Akinnusi M, Jaoude P, El-Solh AA. Cardiovascular mortality in obstructive sleep apnoea treated with continuous positive airway pressure or oral appliance: an observational study. Respirology. 2013;18:1184-90. doi:10.1111/resp. 12140.

65. Galic T, Bozic J, Ivkovic N, Gunjaca G, Ticinovic TK, Dogas Z. Effects of mandibular advancement device treatment on arterial stiffness and glucose metabolism in patients with mild to moderate obstructive sleep apnea: a prospective 1 year study. Sleep Breath. 2016;20:69-77. doi:10.1007/s11325-015-1186-y.

66. Lin CC, Wang HY, Chiu CH, Liaw SF. Effect of oral appliance on endothelial function in sleep apnea. Clin Oral Investig. 2015;19: 437-44. doi:10.1007/s00784-014-1234-1.

67. Hoekema A, Voors AA, Wijkstra PJ, Stegenga B, van der Hoeven JH, Tol CG, et al. Effects of oral appliances and CPAP on the left ventricle and natriuretic peptides. Int J Cardiol. 2008;128:232-9. doi:10.1016/j.ijcard.2007.06.016.

68. Phillips CL, Grunstein RR, Darendeliler MA, Mihailidou AS, Srinivasan VK, Yee BJ, et al. Health outcomes of continuous positive airway pressure versus oral appliance treatment for obstructive sleep apnea: a randomized controlled trial. Am J Respir Crit Care Med. 2013;187:879-87. doi:10.1164/rccm.2012122223OC

69. Dieltjens M, Braem MJ, Vroegop AV, Wouters K, Verbraecken JA, De Backer WA, et al. Objectively measured vs self-reported compliance during oral appliance therapy for sleep-disordered breathing. Chest. 2013;144:1495-502. doi:10.1378/chest.130613.

70. Gong X, Zhang J, Zhao Y, Gao X. Long-term therapeutic efficacy of oral appliances in treatment of obstructive sleep apneahypopnea syndrome. Angle Orthod. 2013;83:653-8. doi:10. 2319/060412-463.1.

71. Gonzalez M, Macias-Escalada E, Cobo J, Fernandez Mondragon MP, Gomez-Moreno G, Martinez-Martinez M, et al. Can treatment with statins have a negative influence on the tolerance of mandibular advancement devices? Sleep Breath. 2016;20:13636. doi:10.1007/s11325-016-1399-8.

72. Cohen-Levy J, Petelle B, Pinguet J, Limerat E, Fleury B. Forces created by mandibular advancement devices in OSAS patients: a pilot study during sleep. Sleep Breath. 2013;17:781-9. doi:10. 1007/s11325-012-0765-4.

73. Doff MH, Finnema KJ, Hoekema A, Wijkstra PJ, de Bont LG, Stegenga B. Long-term oral appliance therapy in obstructive sleep apnea syndrome: a controlled study on dental side effects. Clin Oral Investig. 2013;17:475-82. doi:10.1007/s00784-012-0737-x.

74. Perez CV, de Leeuw R, Okeson JP, Carlson CR, Li HF, Bush HM, et al. The incidence and prevalence of temporomandibular disorders and posterior open bite in patients receiving mandibular advancement device therapy for obstructive sleep apnea. Sleep Breath. 2013;17:323-32. doi:10.1007/s11325-012-0695-1.

75. Almeida FR, Lowe AA, Otsuka R, Fastlicht S, Farbood M, Tsuiki $\mathrm{S}$. Long-term sequellae of oral appliance therapy in obstructive sleep apnea patients: part 2. Study-model analysis. Am J Orthod Dentofac Orthop. 2006;129:205-13. doi:10.1016/j.ajodo.2005. 04.034 . 
76. Marklund M. Predictors of long-term orthodontic side effects from mandibular advancement devices in patients with snoring and obstructive sleep apnea. Am J Orthod Dentofac Orthop. 2006;129: 214-21. doi:10.1016/j.ajodo.2005.10.004.

77. Pliska BT, Nam H, Chen H, Lowe AA, Almeida FR. Obstructive sleep apnea and mandibular advancement splints: occlusal effects and progression of changes associated with a decade of treatment. J Clin Sleep Med. 2014;10:1285-91. doi:10.5664/jcsm.4278. The longest follow-up of dental side-effects of OA therapy in a large sample

78. Marklund M. Long-term efficacy of an oral appliance in early treated patients with obstructive sleep apnea. Sleep Breath. 2016;20:689-94. doi:10.1007/s11325-015-1280-1. The longest follow-up of $\mathrm{OA}$ therapy

79. Marklund M, Franklin KA, Persson M. Orthodontic side-effects of mandibular advancement devices during treatment of snoring and sleep apnoea. Eur J Orthod. 2001;23:135-44.

80. Pantin CC, Hillman DR, Tennant M. Dental side effects of an oral device to treat snoring and obstructive sleep apnea. Sleep. 1999;22:237-40.

81. Doff MH, Hoekema A, Wijkstra PJ, van der Hoeven JH, Huddleston Slater JJ, de Bont LG, et al. Oral appliance versus continuous positive airway pressure in obstructive sleep apnea syndrome: a 2-year follow-up. Sleep. 2013;36:1289-96. doi:10. 5665/sleep.2948.

82. Fransson AM, Tegelberg A, Leissner L, Wenneberg B, Isacsson G. Effects of a mandibular protruding device on the sleep of patients with obstructive sleep apnea and snoring problems: a 2-year follow-up. Sleep Breath. 2003;7:131-41. doi:10.1007/s11325003-0131-7.

83. Gauthier L, Laberge L, Beaudry M, Laforte M, Rompre PH, Lavigne GJ. Mandibular advancement appliances remain effective in lowering respiratory disturbance index for $2.5-4.5$ years. Sleep Med. 2011;12:844-9. doi:10.1016/j.sleep.2011.05.004.

84. Ghazal A, Sorichter S, Jonas I, Rose EC. A randomized prospective long-term study of two oral appliances for sleep apnoea treatment. J Sleep Res. 2009;18:321-8. doi:10.1111/j.1365-2869. 2009.00738.x.

85. Marklund M, Sahlin C, Stenlund H, Persson M, Franklin KA. Mandibular advancement device in patients with obstructive sleep apnea: long-term effects on apnea and sleep. Chest. 2001;120: 162-9.

86. Rose EC, Barthlen GM, Staats R, Jonas IE. Therapeutic efficacy of an oral appliance in the treatment of obstructive sleep apnea: a 2-year follow-up. Am J Orthod Dentofac Orthop. 2002;121:273-9.

87. Wiman Eriksson E, Leissner L, Isacsson G, Fransson A. A prospective 10-year follow-up polygraphic study of patients treated with a mandibular protruding device. Sleep Breath. 2015;19:393401. doi:10.1007/s11325-014-1034-5.

88. Walker-Engstrom ML, Tegelberg A, Wilhelmsson B, Ringqvist I. 4-year follow-up of treatment with dental appliance or uvulopalatopharyngoplasty in patients with obstructive sleep apnea: a randomized study. Chest. 2002;121:739-46.
89. Peppard PE, Young T, Barnet JH, Palta M, Hagen EW, Hla KM. Increased prevalence of sleep-disordered breathing in adults. Am J Epidemiol. 2013;177:1006-14. doi:10.1093/aje/kws342.

90. Senaratna CV, Perret JL, Lodge CJ, Lowe AJ, Campbell BE, Matheson MC, et al. Prevalence of obstructive sleep apnea in the general population: a systematic review. Sleep Med Rev. 2016; doi:10.1016/j.smrv.2016.07.002.

91. McGown AD, Makker HK, Battagel JM, L'Estrange PR, Grant HR, Spiro SG. Long-term use of mandibular advancement splints for snoring and obstructive sleep apnoea: a questionnaire survey. Eur Respir J. 2001;17:462-6.

92. Zhou J, Liu YH. A randomised titrated crossover study comparing two oral appliances in the treatment for mild to moderate obstructive sleep apnoea/hypopnoea syndrome. J Oral Rehabil. 2012;39: 914-22. doi:10.1111/joor.12006.

93. Friedman M, Hamilton C, Samuelson CG, Kelley K, PearsonChauhan K, Taylor D, et al. Compliance and efficacy of titratable thermoplastic versus custom mandibular advancement devices. Otolaryngol Head Neck Surg. 2012;147:379-86. doi:10.1177/ 0194599812439683.

94. Vanderveken OM, Devolder A, Marklund M, Boudewyns AN, Braem MJ, Okkerse W, et al. Comparison of a custom-made and a thermoplastic oral appliance for the treatment of mild sleep apnea. Am J Respir Crit Care Med. 2008;178:197-202. doi:10.1164/ rccm.200701-114OC.

95. Braem M. In vitro retention of a new thermoplastic titratable mandibular advancement device. F1000Res. 2015;4:56. doi:10.12688/ f1000research.6061.1.

96. Nishigawa K, Hayama R, Matsuka Y. Complications causing patients to discontinue using oral appliances for treatment of obstructive sleep apnea. J Prosthodont Res. 2016; doi:10.1016/j.jpor. 2016.08.001.

97. Ringqvist M, Walker-Engstrom ML, Tegelberg A, Ringqvist I. Dental and skeletal changes after 4 years of obstructive sleep apnea treatment with a mandibular advancement device: a prospective, randomized study. Am J Orthod Dentofac Orthop. 2003;124: 53-60. doi:10.1016/S0889540603002403.

98. Marklund M, Legrell PE. An orthodontic oral appliance. Angle Orthod. 2010;80:1116-21. doi:10.2319/012210-46.1.

99. Marshall NS, Wong KK, Cullen SR, Knuiman MW, Grunstein RR. Sleep apnea and 20-year follow-up for all-cause mortality, stroke, and cancer incidence and mortality in the Busselton Health Study cohort. J Clin Sleep Med. 2014;10:355-62. doi:10. $5664 / \mathrm{jcsm} .3600$. Important data that reflect treatment needs of milder OSA

100. Richter K, Adam S, Geiss L, Peter L, Niklewski G. Two in a bed: the influence of couple sleeping and chronotypes on relationship and sleep. An overview. Chronobiol Int. 2016;33:1464-72. doi: 10.1080/07420528.2016.1220388.

101. Tegelberg A, Nohlert E, Bergman LE, Andren A. Bed partners' and patients' experiences after treatment of obstructive sleep apnoea with an oral appliance. Swed Dent J. 2012;36:35-44.

102. Sutherland K, Vanderveken OM, Tsuda H, Marklund M, Gagnadoux F, Kushida CA, et al. Oral appliance treatment for obstructive sleep apnea: an update. J Clin Sleep Med. 2014;10: 215-27. doi:10.5664/jcsm.3460. 